\title{
A Culture Method to Maintain Quiescent Human Hematopoietic Stem Cells
}

\author{
Hiroshi Kobayashi ${ }^{1}$, Keiyo Takubo ${ }^{1}$ \\ ${ }^{1}$ Department of Stem Cell Biology, Research Institute, National Center for Global Health and Medicine
}

\section{Corresponding Author}

Keiyo Takubo

keiyot@gmail.com

\section{Citation}

Kobayashi, H., Takubo, K. A Culture Method to Maintain Quiescent Human Hematopoietic Stem Cells. J. Vis. Exp. (171), e61938, doi:10.3791/61938 (2021).

\section{Date Published}

May 17,2021

DOI

$10.3791 / 61938$

URL

jove.com/video/61938

\section{Abstract}

Human hematopoietic stem cells (HSCs), like other mammalian HSCs, maintain lifelong hematopoiesis in the bone marrow. HSCs remain quiescent in vivo, unlike more differentiated progenitors, and enter the cell cycle rapidly after chemotherapy or irradiation to treat bone marrow injury or in vitro culture. By mimicking the bone marrow microenvironment in the presence of abundant fatty acids, cholesterol, low concentration of cytokines, and hypoxia, human HSCs maintain quiescence in vitro. Here, a detailed protocol for maintaining functional HSCs in the quiescent state in vitro is described. This method will enable studies of the behavior of human HSCs under physiological conditions.

\section{Introduction}

Hematopoietic stem cells (HSCs) and multipotent progenitor cells (MPPs) coordinately form a reservoir for continuous replenishment of differentiated cells to maintain hematopoiesis throughout life in humans ${ }^{1}$. Cell cycle quiescence is a prominent feature of HSCs, differentiating them from MPPs ${ }^{2}$. Conventionally, HSCs are thought to reside at the apex of the hierarchy of the hematopoietic system, producing all differentiated blood cells. This hierarchical model was mostly deduced from transplantation experiments $^{3}$. However, recent studies indicated that the dynamics of HSCs differ in vivo as compared to those in transplantation experiments ${ }^{4,5,6,7}$. Lineage tracing experiments using several barcoding systems revealed that phenotypic murine HSCs are not a unique cell type that contributes to steady-state hematopoiesis, and MPPs, which display limited self-renewal activity upon transplantation settings, continuously supply mature blood cells $s^{4,5,8}$. In contrast, the contribution of HSCs to mature cells is enhanced after bone marrow injury ${ }^{4}$. This may be attributed to drastic alterations in the microenvironment following bone marrow ablation, including bone marrow transplantation. Although applying lineage tracing of murine cells to human cells is 
difficult, phylogenetic analysis combining single-cell-derived colony isolation and whole genome sequencing revealed a similar property of the hematopoietic system, in which both HSCs and MPPs are responsible for the daily production of mature cells ${ }^{7}$. Thus, although transplantation is essential for examining murine or human HSC activity, other experimental models are needed to understand the behaviors of HSCs under physiological conditions.

Culturing methods for HSCs have been studied in detail to understand their clinical applications and characteristics. Human HSCs can be expanded in vitro using a combination of cytokines, reconstitution of extracellular matrices, removal of self-renewal antagonists, co-culture with mesenchymal or endothelial cells, addition of albumin or its replacement, transduction of self-renewal transcription factors, and addition of small-molecule compounds ${ }^{9,10}$. Some of these methods, including addition of small compounds SR $1^{11}$ and $\mathrm{UM} 171^{12}$, have been tested in clinical trials with promising results ${ }^{9}$. Considering the quiescent nature of HSCs in vivo, maintaining HSCs with minimal cell cycling is critical for recapitulating HSC behavior in vitro. Quiescent and proliferating HSCs exhibit differential cell cycle entry ${ }^{13}$, metabolic status ${ }^{14}$, and tolerance against multiple stresses ${ }^{15}$. The methods used to maintain the quiescence of human HSCs in vitro are limited.

By mimicking the microenvironment of the bone marrow (hypoxic and rich in lipids) and optimizing the concentration of cytokines, human HSCs can be maintained undifferentiated and quiescent under culture. Recapitulating the quiescent nature of HSCs in vitro will improve the understanding of the steady state properties of HSCs and enable experimental manipulation of HSCs.

\section{Protocol}

The protocol follows the guidelines of National Center for Global Health and Medicine. All experimental procedures performed on mice are approved by the National Center for Global Health and Medicine animal experiment committee. NOTE: An overview of the protocol is illustrated in Figure 1.

\section{Lipid preparation}

1. Dissolve the following lipids in methanol in glass tubes at the indicated concentrations: sodium palmitate, $16 \mathrm{mg} /$ $\mathrm{mL}$; sodium oleate, $30 \mathrm{mg} / \mathrm{mL}$; and cholesterol, $4 \mathrm{mg} / \mathrm{mL}$. Store the lipid solution at $-30{ }^{\circ} \mathrm{C}$ and thaw the sample before use.

2. Mix the lipid solutions prepared in step 1.1 in a fresh glass tube at the doses necessary to obtain the final concentration of $100 \mu \mathrm{g} / \mathrm{mL}$ palmitate, $100 \mu \mathrm{g} / \mathrm{mL}$ oleate, and $20 \mu \mathrm{g} / \mathrm{mL}$ cholesterol. For instance, when preparing $10 \mathrm{~mL}$ of culture media, mix $62.5 \mu \mathrm{L}$ of palmitate solution, $33 \mu \mathrm{L}$ of oleate solution, and $50 \mu \mathrm{L}$ of cholesterol solution in the glass tube.

3. Evaporate the methanol by passing nitrogen gas through the lipid solution (Figure 2A and 2B). If nitrogen gas is not available, pass air through the solution by using a pipette-aid.

4. Completely evaporate the remaining methanol by heating the glass tube in a water bath at $37^{\circ} \mathrm{C}$ (Figure 2C).

NOTE: The use of a high concentration of $\mathrm{N}_{2}$ gas in confined space is potentially harmful. Although the volume used in the protocol to evaporate methanol is limited and thus is considered as safe, ventilating the room adequately and labeling areas of potentially 
high concentrations of $\mathrm{N}_{2}$ gas is important should an unexpected gas leak occur.

\section{Medium preparation}

1. Prepare Dulbecco's modified Eagle medium (DMEM)/ F12 medium (with HEPES and glutamine). Add penicillin and streptomycin sulfate to the medium to the final concentration of 50 units and $50 \mu \mathrm{g} / \mathrm{mL}$, respectively. DMEM/F12 medium containing antibiotics can be stored at $4{ }^{\circ} \mathrm{C}$ for at least 2 months.

2. Add $4 \% \mathrm{w} / \mathrm{v}$ of bovine serum albumin (BSA) to Dulbecco's modified Eagle medium (DMEM)/F12 medium (with HEPES and glutamine).

3. Adjust the $\mathrm{pH}$ of the medium to $\mathrm{pH} 7.4-7.8$ using $\mathrm{NaOH}$ solution, typically to $\mathrm{pH} 7.6$.

4. Add the medium to the glass tube prepared in step 1. To achieve a solution with maximum solubility, addition of 3-15 $\mathrm{mL}$ medium is recommended.

5. Completely dissolve the lipids by sonication (optimal: more than 20 min of sonication). After the BSA and lipids are dissolved, the sample should be stored at $-80^{\circ} \mathrm{C}$ and used within 2 months. Thaw immediately before use.

6. Add $1 / 1,000$ of the insulin, transferrin, sodium selenite, and ethanol amine (ITS-X) mixture to the DMEM/ F12. Filter the mixed medium using a $0.22 \mu \mathrm{m}$ filter (designated as "culture media"). Before use, add human stem cell factor (SCF) and human thrombopoietin (TPO) to the culture media at a final concentration of $3 \mathrm{ng} / \mathrm{mL}$ each. After adding the cytokines and ITS-X, the medium cannot be stored.

7. Staining buffer: Add 10\% FCS to Ca- and Mg-free phosphate-buffered saline (PBS). This solution can be stored at $4{ }^{\circ} \mathrm{C}$ for 2 weeks.
8. Thawing media: Add 10\% FCS to the DMEM/F12. This solution is single-use.

9. Cytokine stock solution: Dissolve each human SCF or human TPO in PBS (Ca- and Mg-free) at $20 \mu \mathrm{g} / \mathrm{mL}$. This solution can be stored at $-80{ }^{\circ} \mathrm{C}$ for at least one year without a loss of activity. Once thawed, store the stock solution at $4{ }^{\circ} \mathrm{C}$ and use within 1 month.

NOTE: Examine the lot after every purchase to avoid variation in the contaminants in BSA. Culture HSCs at the same time with different batches of BSA and examine the phenotypic HSC number at day 7 as described below. If a BSA batch shows a low number or frequency of CD34+ cells (e.g. less than a half the number of input cells), avoid using this batch.

\section{Preparation of human bone marrow CD34 cells}

1. Purchase human $\mathrm{CD} 34^{+}$bone marrow cells and store the cells in liquid nitrogen until use. Alternatively, bone marrow cells from a healthy volunteer or fresh cord blood cells can be used upon approval by the institute ethical committee and donor consent.

2. Warm $10 \mathrm{~mL}$ of thawing media in a $15 \mathrm{~mL}$ conical tube in a $37^{\circ} \mathrm{C}$ water bath.

3. Thaw the frozen cells in vials in a $37^{\circ} \mathrm{C}$ water bath within 2 min. After wiping the vial with $70 \%$ ethanol to remove contaminants, transfer the cells to the $15 \mathrm{~mL}$ conical tube containing the pre-warmed medium from step 3.2.

4. Centrifuge the $15 \mathrm{~mL}$ tube at $200 \times \mathrm{g}$ for $15 \mathrm{~min}$ at room temperature. Aspirate the supernatant carefully to keep the pellet intact (leaving $<50 \mu \mathrm{L}$ of medium). Resuspend the cells with the remaining medium and transfer them to a $1.5 \mathrm{~mL}$ tube on ice. 
NOTE: Exposure to human-derived samples directly in the mucosa including the eye or wounded tissue may cause infection by known or unknown pathogens; thus, gloves and eyeglasses are recommended when handling human cells. Even if the purchased $\mathrm{CD} 34^{+}$cells test negative for hepatitis B virus (HBV), hepatitis C virus (HCV), and human immunodeficiency virus 1 (HIV1), careful monitoring should be performed according to institutional guidelines if an exposure incidence occurs. Follow the institutional guidelines when disposing of materials exposed to human cells.

\section{Sorting HSCs}

1. Label the cells with fluorochrome-conjugated antibodies. Mix $50 \mu \mathrm{L}$ of staining buffer plus $10 \mu \mathrm{L}$ of anti-CD34-FITC, $2 \mu \mathrm{L}$ of anti-CD38-PerCP-Cy5.5, $5 \mu \mathrm{L}$ of anti-CD90-PECy7, and $10 \mu \mathrm{L}$ of anti-CD45RA-PE. Resuspend the cell pellet in the antibody mixture. Incubate the cells for 30 $\min$ at $4{ }^{\circ} \mathrm{C}$ in the dark.

2. Add $1 \mathrm{~mL}$ of staining buffer to wash the antibodies. Centrifuge the tubes at $340 \times g$ for $5 \mathrm{~min}$ at $4{ }^{\circ} \mathrm{C}$. Discard the supernatant.

3. Resuspend the cell pellet in $0.5 \mathrm{~mL}$ of staining buffer + $0.1 \%$ propidium iodide. Transfer the suspension into a 5 $\mathrm{mL}$ tube using a $40 \mu \mathrm{m}$ filter.

4. Gate the phenotypic HSCs within the $\mathrm{PI}^{-} \mathrm{CD} 34^{+} \mathrm{CD} 38^{-} \mathrm{CD} 90^{+} \mathrm{CD}_{45 \mathrm{RA}^{-}}$fraction using the FACS Aria-Illu and sort the cells into a $1.5 \mathrm{~mL}$ tube filled with $500 \mu \mathrm{L}$ of culture media (Figure 3). Using the gating strategy shown in Figure 3, $10 \%$ of $\mathrm{CD}^{+} 4^{+}$cells are expected to be phenotypic HSCs. Record the sorted cell number to calculate the volume of media to resuspend the cells in step 5.3.
NOTE: The gating strategy is performed as described previously ${ }^{16}$ while omitting the lineage marker staining given the low expression of lineage markers in the CD34+CD38- fraction from healthy individuals ${ }^{17}$.

5. Centrifuge the sorted cells at $340 \times g$ for $5 \mathrm{~min}$ at 4 ${ }^{\circ} \mathrm{C}$ and discard the supernatant. Carefully aspirate the supernatant to ensure that the pellet remains intact.

6. Store the sorted cells on ice until culture.

NOTE: Fluorescence compensation of spectral overlap should be performed during the first experiment.

\section{Cell culture}

1. Transfer $200 \mu \mathrm{L}$ of the culture media containing cytokines prepared in step 2 into flat-bottom 96-well plates.

2. To avoid evaporation of the medium, fill all unused wells with $100-200 \mu \mathrm{L}$ of PBS.

3. Resuspend the sorted HSCs in culture media without cytokines at 60 cells $/ \mu \mathrm{L}$.

4. Aliquot $600 \mathrm{HSCs} /$ well ( $10 \mu \mathrm{L}$ of cell suspension) into each well. The cell number can be altered. Fewer than 300 cells will lead to larger technical variation, and thus more wells per condition are needed to detect biological differences. Culturing more than 1000 cells in a single well should be avoided because of cytokine/nutrient deprivation or accumulation of unfavorable cytokines/ chemokines.

5. Culture the cells in a humidified multi-gas incubator at 37 ${ }^{\circ} \mathrm{C}$ in a $5 \% \mathrm{CO}_{2}$ and $1 \% \mathrm{O}_{2}$ atmosphere.

6. For cultures over 7 days, replacing half the media volume every 3-4 days is recommended. Carefully aspirate 100 $\mu \mathrm{L}$ of media by pipetting and add $100 \mu \mathrm{L}$ of newly 
prepared culture media containing cytokines to each well.

The culture media should be pre-warmed at $37^{\circ} \mathrm{C}$.

\section{Analysis of marker phenotypes using flow cytometry}

NOTE: Although the cells should be analyzed after 7 days of culture, the culture duration can be changed.

1. Discard $170 \mu \mathrm{L}$ of the medium by using an 8-channel pipette.

2. Label the cells with the antibody mixture. Mix $0.5 \mu \mathrm{L}$ of anti-CD34-FITC, $0.1 \mu \mathrm{L}$ of anti-CD38-PerCP-Cy5.5, 0.25 $\mu \mathrm{L}$ of anti-CD90-PE-Cy7, $0.5 \mu \mathrm{L}$ of anti-CD45RA-PE, and $9 \mu \mathrm{L}$ of staining buffer per well. Add $10 \mu \mathrm{L}$ of the mixture to the 96-well plate and incubate the cells for $30 \mathrm{~min}$ at $4{ }^{\circ} \mathrm{C}$ in the dark.

3. To wash the antibodies, add $100 \mu \mathrm{L}$ of staining buffer to the wells and centrifuge the plates at $400 \times g$ for $5 \mathrm{~min}$ at $4{ }^{\circ} \mathrm{C}$ using low acceleration and medium deceleration.

4. Carefully aspirate $100 \mu \mathrm{L}$ of the supernatant to maintain the cells on the bottom of the wells, then resuspend the cells in $200 \mu \mathrm{L}$ of staining buffer $+0.1 \% \mathrm{v} / \mathrm{v}$ of $\mathrm{PI}$ $+1 \% \mathrm{v} / \mathrm{v}$ of fluorescent microspheres (e.g., Flow-Check Fluorospheres).

5. Set up the flow cytometry instrument. Acquire data for the samples in fast mode with mixed sample mode on and uptake volumes of $100 \mu \mathrm{L}$.

6. Export the data in FCS format and analyze it using software such as FlowJo. Cell numbers can be determined using the fluorescent microsphere bead count. For instance, if the researcher adds 2000 beads per well and the bead count is 700 , multiply the cell number of each fraction by $2000 / 700$ to estimate the total cell number of the fraction in the well.
NOTE: Fluorescent microspheres are toxic to cultured cells because of the presence of formaldehyde. This may induce cell death during analysis. Minimize the number of wells ( $<50$ wells) analyzed continuously to avoid bias.

\section{Transplantation of human HSCs}

NOTE: Repopulation activity of cultured cells are validated by transplantation to immunodeficient mice. All procedures must be approved by animal experiment committees or their equivalents.

1. As donors, prepare a sufficient number of 8-12-week immunodeficient NOD-SCID-II2rg-null (NOG) mice. As NOG mice are highly susceptible to infection, keep the breeding cages as clean as possible and feed the mice with a sterilized diet and water.

2. Culture an adequate number of HSCs for transplantation as described in step 5. For instance, when 5000 HSCs (day 0 equivalent) are transplanted to 6 recipient mice, culture $35,000-40,000$ HSCs in 40 wells of a 96 -well plate (200 $\mu \mathrm{L}$ of culture media per well) or in 8 wells of a $24-$ well plate $(1 \mathrm{~mL}$ of culture media per well). Culture the cells for 2 weeks with half-media changes every 3-4 days in a humidified multi-gas incubator at $37^{\circ} \mathrm{C}$ with $5 \% \mathrm{CO}_{2}$ and $1 \% \mathrm{O}_{2}$. The culture duration can be altered.

3. Irradiate NOG mice at $2.5 \mathrm{~Gy}$ at $6-24 \mathrm{~h}$ prior to transplantation.

4. Collect the cultured HSCs in $1.5 \mathrm{~mL}$ tubes. Centrifuge the tubes at $340 \times g$ for $5 \min$ at $4^{\circ} \mathrm{C}$.

5. Carefully aspirate the supernatants and resuspend the cells in sterile ice-cold staining buffer at a cell density of 5000 HSCs (day 0 equivalent) per $200 \mu \mathrm{L}$. Transfer this suspension to $3 \mathrm{~mL}$ polypropylene tubes. To sterilize the staining buffer, filter it using a $0.22 \mu \mathrm{m}$ filter. 
6. Before transplantation, anesthetize the mice by sevoflurane or isoflurane inhalation.

7. To transplant 5000 of cultured HSCs (day 0 equivalent), inject $200 \mu \mathrm{L}$ of the cell suspension into the tail vein or retro orbital sinus of NOG mice irradiated in step 7.1 using a $1 \mathrm{~mL}$ syringe and 27 -gauge needle. Freshly isolated or thawed bone marrow HSCs can be transplanted as a control. Gloves should be sterilized with $70 \% \mathrm{v} / \mathrm{v}$ ethanol between each procedure.

\section{Analysis of the frequency of human-derived cells in the peripheral blood}

1. To examine the repopulation of human cells, collect the peripheral blood at 1,2 , and 3 months after transplantation.

2. Before collecting the peripheral blood, anesthetize the mice by sevoflurane inhalation.

3. Collect $40-80 \mu \mathrm{L}$ of peripheral blood from the retroorbital sinus using heparinized glass capillary tubes and suspend this sample in $1 \mathrm{~mL}$ of PBS + heparin $(1 \mathrm{U} / \mathrm{mL})$ in $1.5 \mathrm{~mL}$ tubes.

4. Centrifuge the blood suspension at $340 \times g$ for $3 \mathrm{~min}$ at $4{ }^{\circ} \mathrm{C}$. Discard the supernatant and resuspend the pellet in $1 \mathrm{~mL}$ of PBS $+1.2 \% \mathrm{w} / \mathrm{v}$ dextran $(200 \mathrm{kDa})$ for $45 \mathrm{~min}$ at room temperature.

5. Transfer the supernatant to another $1.5 \mathrm{~mL}$ tube and centrifuge at $340 \times g$ for $3 \mathrm{~min}$.

6. For red blood cell lysis, resuspend the cells in $0.17 \mathrm{M}$ $\mathrm{NH}_{4} \mathrm{Cl}$ for $5 \mathrm{~min}$.

7. Centrifuge the cell suspension $340 \times g$ for 3 min at $4{ }^{\circ} \mathrm{C}$. Resuspend the cells in $50 \mu \mathrm{L}$ of staining buffer containing
$0.3 \mu \mathrm{L}$ of anti-mouse Fc-block. Incubate this sample at 4 ${ }^{\circ} \mathrm{C}$ for 5 min.

8. Add the following antibodies for surface marker staining: $0.3 \mu \mathrm{L}$ of mouse CD45-PE-Cy7, $0.3 \mu \mathrm{L}$ mouse Ter-119PE-Cy7, 0.3 $\mu \mathrm{L}$ of human CD45-BV421, 0.3 $\mu \mathrm{L}$ of human CD13-PE, $1.2 \mu \mathrm{L}$ of human CD33-PE, $0.3 \mu \mathrm{L}$ of human CD19-APC, $0.3 \mu \mathrm{L}$ of human CD3-APC-Cy7. Incubate the cells at $4{ }^{\circ} \mathrm{C}$ for $15 \mathrm{~min}$.

9. Wash once with $1 \mathrm{~mL}$ of staining buffer and centrifuge at $340 \times g$ for $5 \min$ at $4{ }^{\circ} \mathrm{C}$.

10. Discard the supernatant and resuspend the cells in 200 $\mu \mathrm{L}$ of staining buffer $+0.1 \% \mathrm{v} / \mathrm{v}$ of $\mathrm{PI}$.

11. Transfer the cell suspension to a 96-well flat-bottom plate and acquire data using the flow cytometer in fast mode with the mix sample mode on and an uptake volume of $100 \mu \mathrm{L}$.

12. Export the data in FCS format for analysis using software such as FlowJo.

13. Set up the flow cytometer. Acquire data for the samples in fast mode with the mix sample mode on and an uptake volume of $100 \mu \mathrm{L}$.

14. Export the data in FCS format for analysis using software such as FlowJo. 


\section{Representative Results}

After 7 days of culturing the purified HSCs, up to $80 \%$ of cells displayed marker phenotypes of CD $34^{+}$CD38- (Figure 4A). The total cell number depended on the cytokine concentration (Figure 4B). Higher concentrations of SCF and TPO induced entry into the cell cycle, proliferation, and differentiation (Figure 4B). The number of phenotypic HSCs characterized by the marker phenotypes of $\mathrm{CD} 34^{+} \mathrm{CD} 38^{-} \mathrm{CD} 90^{+} \mathrm{CD} 45 \mathrm{RA}^{-}$ increased in proportion to the SCF or TPO concentrations (Figure 4B), whereas the frequency among the total cells decreased (Figure 4C). Total cell numbers were equal in the $1.5 \mathrm{ng} / \mathrm{mL} \mathrm{SCF}$ and $4 \mathrm{ng} / \mathrm{mL}$ TPO and the $3 \mathrm{ng} / \mathrm{mL}$ SCF
3 and $2 \mathrm{ng} / \mathrm{mL}$ TPO combinations, suggesting that HSCs are quiescent during minimal cell cycle activation. Given the individual differences, cytokine titration is recommended for each bone marrow donor.

Following 3 months of transplantation of cultured adult bone marrow HSCs, reconstitution can be evaluated as their frequency in the peripheral blood of human CD45+ murine CD45- Ter119- cells. Three lineages including CD19+ B cells, CD13/CD33+ myeloid cells, and CD3+ T cells were reconstituted in NOG mice transplanted with either freshly thawed HSCs or cultured HSCs (Figure 5).

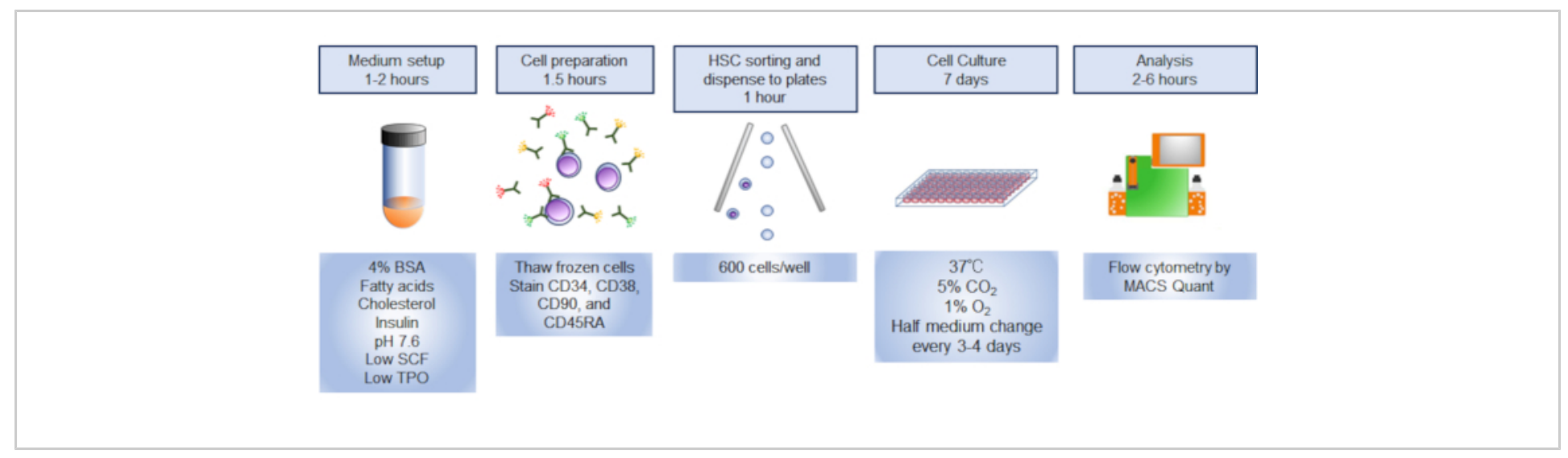

Figure 1. Overview of the procedure. Graphical summary of the procedure involved sorting, culturing, and analyzing human hematopoietic stem cells (HSCs). Please click here to view a larger version of this figure. 
A

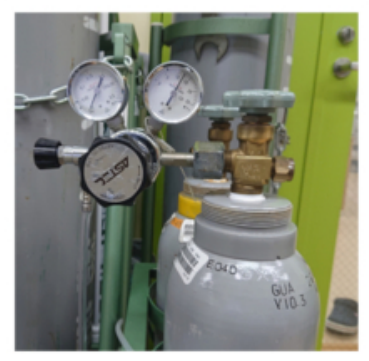

B

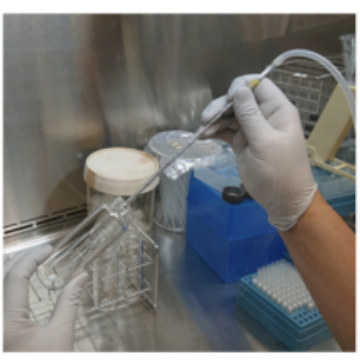

C

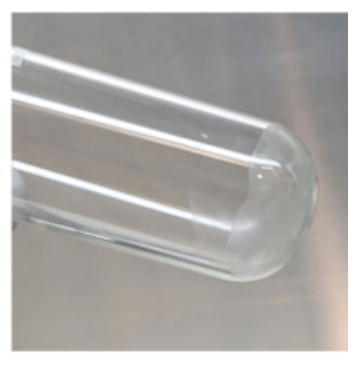

Figure 2.Procedure to evaporate methanol from the lipid solution. A) Nitrogen gas cylinder with a gas regulator. B) Procedure for passing nitrogen gas through the lipid solution dissolved in methanol. C) Lipids adhering to the bottom of the glass tube. Please click here to view a larger version of this figure.
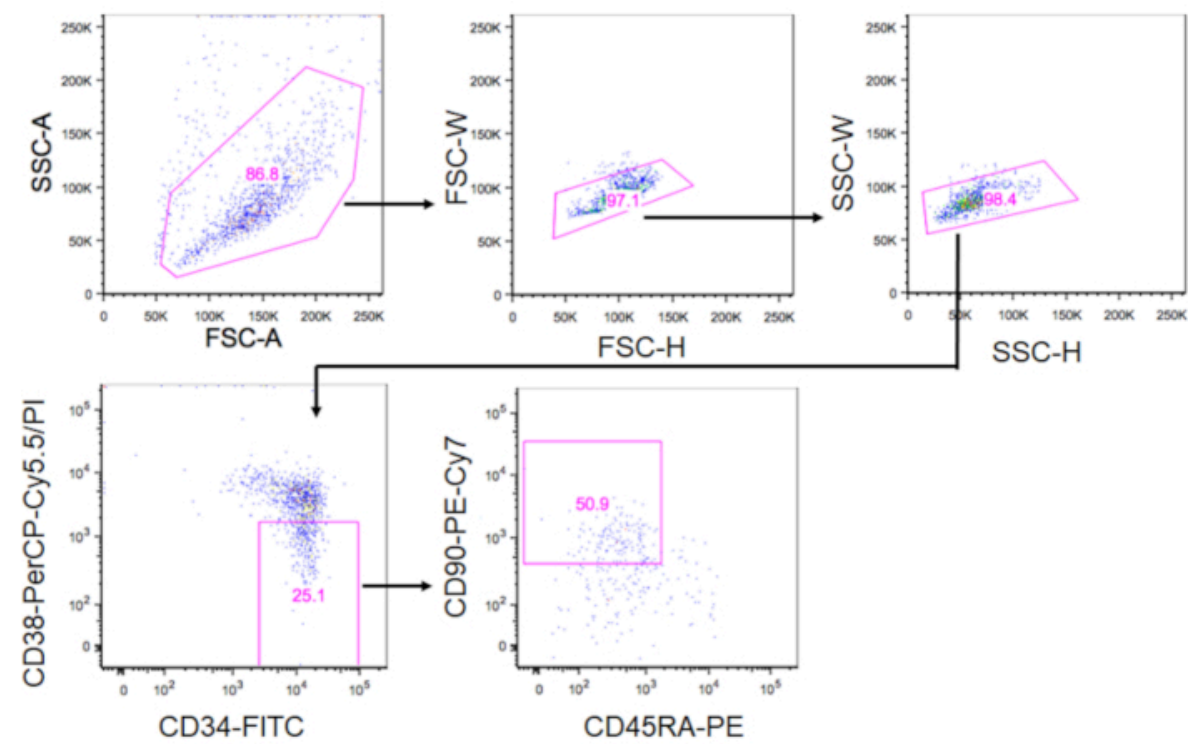

Figure 3. Gating strategy for sorting HSCs. The plots show gated $C D 34^{+} \mathrm{CD} 38^{-} \mathrm{CD} 90^{+} \mathrm{CD} 45 \mathrm{RA}^{-}$cells. Approximately $10 \%$ of $\mathrm{CD}_{3}{ }^{+}$cells were phenotypic HSCs. Please click here to view a larger version of this figure. 

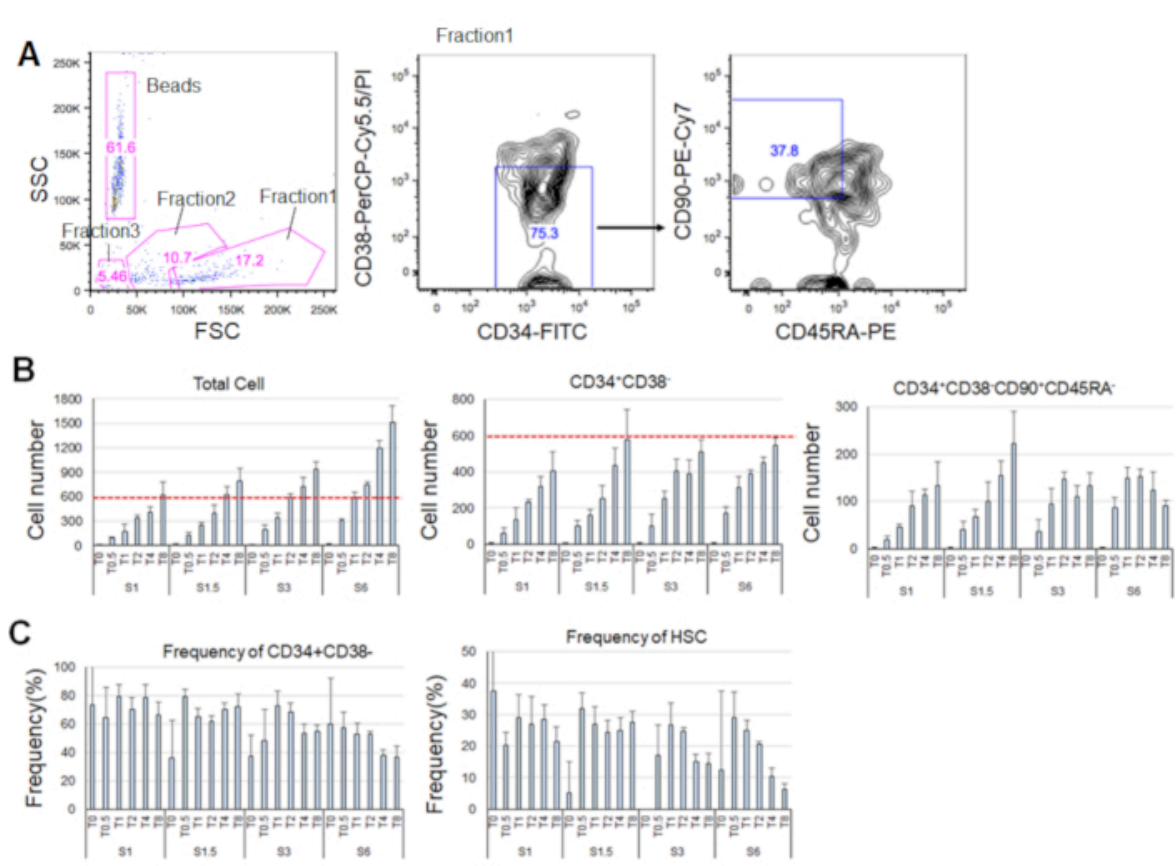

Figure 4. Representative cell numbers after 7 days of culturing. A) Representative fluorescence-activated cell sorting plot after culturing the HSCs in SCF $(3 \mathrm{ng} / \mathrm{mL})$ and TPO $(2 \mathrm{ng} / \mathrm{mL})$. Fraction 1 was enriched for live cells, fraction 2 was enriched for dead cells, and fraction 3 was enriched for debris. Numbers colored in pink indicate the frequency (\%) of the gated fraction. B) Number of all HSCs, CD $34^{+} \mathrm{CD} 38^{-}$cells, and CD $34^{+} \mathrm{CD} 38^{-} \mathrm{CD}^{-} \mathrm{O}^{+} \mathrm{CD} 45 \mathrm{RA}^{-}$cells after culturing $600 \mathrm{HSCs}$ under the indicated cytokine conditions. Red dashed lines indicate the initial number of input cells. S: SCF, T: TPO. Mean \pm standard deviation, $n=4$. Numbers following $S$ and $T$ indicate the concentration $(\mathrm{ng} / \mathrm{mL})$ of each cytokine. C) Frequency of $\mathrm{CD} 34^{+} \mathrm{CD} 38^{-}$and $\mathrm{CD} 34^{+} \mathrm{CD} 38^{-} \mathrm{CD}^{+} 0^{+} \mathrm{CD}_{45 \mathrm{RA}^{-}}$cells under the indicated cytokine conditions. S: SCF, T: TPO. Mean \pm standard deviation, $n=4$. The error bars for cells cultured in SCF $(1 \mathrm{ng} / \mathrm{mL})$ and TPO $(0 \mathrm{ng} / \mathrm{mL})$ were omitted because of their high values (37.7 and 47.9, respectively). Please click here to view a larger version of this figure. 


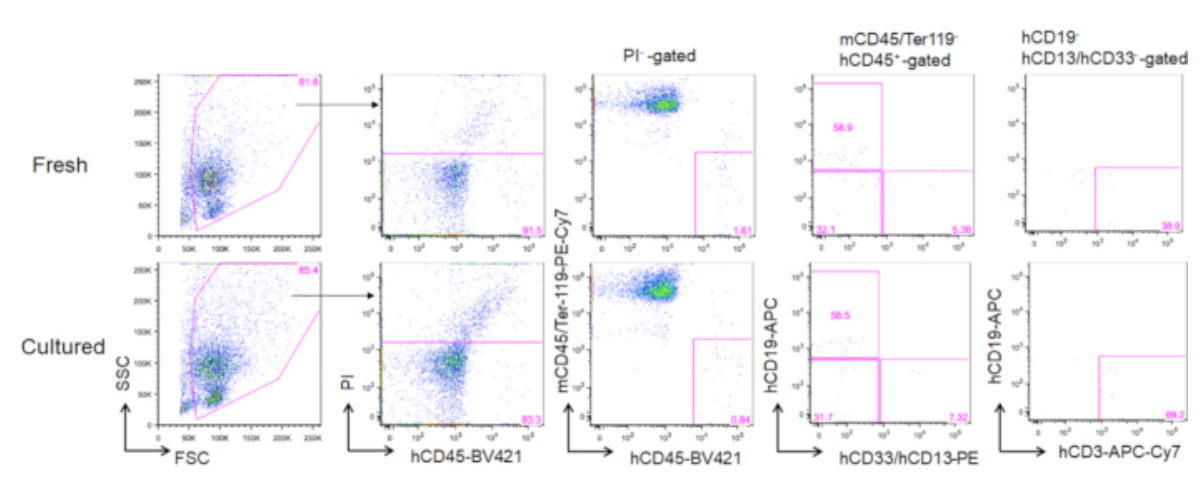

Figure 5. Representative FACS plots of donor mice following 3 months of transplantation. A total of 5000 freshly thawed (upper panels) and 2-week cultured HSCs ( $3 \mathrm{ng} / \mathrm{mL}$ SCF and $3 \mathrm{ng} / \mathrm{mL}$ TPO; lower panels) were transplanted into NOG mice. hCD19 marks human B cells, hCD13 and hCD33 mark human myeloid cells, and hCD3 marks human T cells. Please click here to view a larger version of this figure.

\section{Discussion}

Recently, several methods for expanding HSCs with minimal differentiation have been reported $^{18,19,20,21}$. Although these methods are excellent, HSCs are forced to activate their cell cycles in the presence of high levels of cytokines, which differs from the in vivo situation in which HSCs show minimal cycling. This protocol is useful for maintaining HSCs as quiescent, as observed in vivo, by recapitulating the bone marrow microenvironment.

By culturing human HSCs under low cytokine, lipid-rich, and hypoxic conditions, HSCs showed minimal cycling while maintaining their marker phenotypes. The critical step in this protocol is the preparation of medium containing a high concentration of fatty acids and cholesterol and low cytokine concentrations and culture under hypoxia (Step 1, Step 2, and Step 4). Without cholesterol and/or fatty acids, the maintenance rate of HSCs under low cytokine concentrations decreases ${ }^{22}$. Culturing of cells under hypoxic conditions is also important, as reported previously ${ }^{23}$.
The culture conditions were similar to those used for murine HSCs, except for the cytokine concentrations. Murine HSCs survive without TPO, whereas human HSCs require at least 2 $\mathrm{ng} / \mathrm{mL}$ of TPO with $3 \mathrm{ng} / \mathrm{mL}$ of SCF${ }^{22}$. As the concentration of TPO is much higher than that in human serum $(\sim 100 \mathrm{pg} / \mathrm{mL})$, the conditions used in this protocol may be missing specific factors to support the survival of human HSCs. FLT3 is expressed on human $\mathrm{HSCs}^{24}$. Addition of its ligand FLT3LG slightly decreases the requirement for TPO to maintain $\mathrm{HSCs}^{22}$.

Human HSCs require higher concentrations of cholesterol as compared to murine HSCs, presumably because of the inability to induce the expression of cholesterolsynthesizing enzymes and susceptibility to lipotoxicity under high concentrations $(>400 \mu \mathrm{g} / \mathrm{mL})$ of fatty acids ${ }^{22}$. Although only the combination of palmitic, oleic, linoleic, and stearic acids was tested, which are abundantly found in the human serum, other combinations of lipids should be evaluated 
to reduce lipotoxicity and improve the rate of maintaining functional HSCs.

Although the repopulation activity of cultured human HSCs in immunodeficient mice after two weeks of culture has been confirmed $^{22}$, this culture system does not fully recapitulate the niche functions of HSCs in vivo. The expression of CD45RA has been reported to increase and the repopulation capacity is inferior to that of freshly sorted HSCs ${ }^{22}$. However, the concentrations of nutrients, such as glucose, amino acid, pyruvate, and insulin, which are added to the medium at supraphysiological levels, can be optimized. Contaminants in BSA may also compromise the maintenance of $\mathrm{HSCs}^{18,25}$. In addition, some cultured cells undergo cell death, whereas others undergo cell division; thus, the maintenance of the total cell number may not indicate the quiescent status of each cell.

Despite these limitations, the culture conditions described in the protocol developed in this study will help advance the research and engineering of HSCs, particularly under nearphysiological conditions. Culture conditions that maintain HSCs with minimal differentiation and cycling activity would be suitable for testing biological and chemical compounds specifically acting on HSCs, manipulating HSCs via lentivirus transduction or genome editing without the loss of stemness, and elucidating the initial step of transformation induced by leukemia-associated genes.

\section{Disclosures}

The authors declare no conflict of interest associated with this study.

\section{Acknowledgments}

We thank M. Haraguchi and S. Tamaki for technical support and laboratory management and K. Shiroshita for taking photographs. HK was supported in part by the KAKENHI Grant from MEXT/JSPS (grant no. 19K17847) and National Center for Global Health and Medicine. KT was supported in part by KAKENHI Grants from MEXT/JSPS (grant nos. 18H02845 and 18K19570), National Center for Global Health and Medicine (grant nos. 26-001 and 19A2002), AMED (grant nos. JP18ck0106444, JP18ae0201014, and JP20bm0704042), Ono Medical Research Foundation, Kanzawa Medical Research Foundation, and Takeda Science Foundation.

\section{References}

1. Scala, S., Aiuti, A. In vivo dynamics of human hematopoietic stem cells: novel concepts and future directions. Blood Advances. 3 (12), 1916-1924 (2019).

2. Trumpp, A., Essers, M., Wilson, A. Awakening dormant haematopoietic stem cells. Nature Reviews Immunology. 10 (3), 201-209 (2010).

3. Laurenti, E., Gottgens, B. From haematopoietic stem cells to complex differentiation landscapes. Nature. $\mathbf{5 5 3}$ (7689), 418-426 (2018).

4. Sun, J. et al. Clonal dynamics of native haematopoiesis. Nature. 514 (7522), 322-327 (2014).

5. Busch, K. et al. Fundamental properties of unperturbed haematopoiesis from stem cells in vivo. Nature. $\mathbf{5 1 8}$ (7540), 542-546 (2015).

6. Lee-Six, H. et al. Population dynamics of normal human blood inferred from somatic mutations. Nature. 561 (7724), 473-478 (2018).

7. Osorio, F. G. et al. Somatic Mutations Reveal Lineage Relationships and Age-Related Mutagenesis in Human Hematopoiesis. Cell Reports. 25 (9), 2308-2316.e2304 (2018). 
8. Rodriguez-Fraticelli, A. E. et al. Clonal analysis of lineage fate in native haematopoiesis. Nature. 553 (7687), 212-216 (2018).

9. Pineault, N., \& Abu-Khader, A. Advances in umbilical cord blood stem cell expansion and clinical translation. Experimental Hematology. 43 (7), 498-513 (2015).

10. Wilkinson, A. C., Igarashi, K. J., \& Nakauchi, H. Haematopoietic stem cell self-renewal in vivo and ex vivo. Nature Reviews Genetics. 21 (9), 541-554 (2020).

11. Wagner, J. E. et al. Phase I/II Trial of StemRegenin-1 Expanded Umbilical Cord Blood Hematopoietic Stem Cells Supports Testing as a Stand-Alone Graft. Cell Stem Cell. 18 (1), 144-155 (2016).

12. Cohen, S. et al. Hematopoietic stem cell transplantation using single UM171-expanded cord blood: a singlearm, phase 1-2 safety and feasibility study. Lancet Haematology. 7 (2), e134-e145 (2020).

13. Laurenti, E. et al. CDK6 levels regulate quiescence exit in human hematopoietic stem cells. Cell Stem Cell. 16 (3), 302-313 (2015).

14. Ito, K., \& Suda, T. Metabolic requirements for the maintenance of self-renewing stem cells. Nature Reviews Molecular Cell Biology. 15 (4), 243-256 (2014).

15. Mendelson, A., \& Frenette, P. S. Hematopoietic stem cell niche maintenance during homeostasis and regeneration. Nature Medicine. 20 (8), 833-846 (2014).

16. Majeti, R., Park, C. Y., \& Weissman, I. L. Identification of a hierarchy of multipotent hematopoietic progenitors in human cord blood. Cell Stem Cell. 1 (6), 635-645 (2007).

17. Xie, W. et al. Detection of molecular targets on the surface of CD34+CD38- bone marrow cells in myelodysplastic syndromes. Cytometry A. 77 (9), 840-848 (2010).

18. Wilkinson, A. C. et al. Long-term ex vivo haematopoietic-stem-cell expansion allows nonconditioned transplantation. Nature. 571 (7763), 117-121 (2019).

19. Bai, T. et al. Expansion of primitive human hematopoietic stem cells by culture in a zwitterionic hydrogel. Nature Medicine. 25 (10), 1566-1575 (2019).

20. Boitano, A. E. et al. Aryl hydrocarbon receptor antagonists promote the expansion of human hematopoietic stem cells. Science. 329 (5997), 1345-1348 (2010).

21. Fares, I. et al. Cord blood expansion. Pyrimidoindole derivatives are agonists of human hematopoietic stem cell self-renewal. Science. 345 (6203), 1509-1512 (2014).

22. Kobayashi, H. et al. Environmental Optimization Enables Maintenance of Quiescent Hematopoietic Stem Cells Ex Vivo. Cell Reports. 28 (1), 145-158 e149 (2019).

23. Danet, G. H., Pan, Y., Luongo, J. L., Bonnet, D. A., \& Simon, M. C. Expansion of human SCID-repopulating cells under hypoxic conditions. Journal of Clinical Investigation. 112 (1), 126-135 (2003).

24. Kikushige, Y. et al. Human Flt3 is expressed at the hematopoietic stem cell and the granulocyte/ macrophage progenitor stages to maintain cell survival. Journal of Immunology. 180 (11), 7358-7367 (2008).

25. leyasu, A. et al. An All-Recombinant Protein-Based Culture System Specifically Identifies Hematopoietic Stem Cell Maintenance Factors. Stem Cell Reports. 8 (3), 500-508 (2017). 